\title{
Potentiation of Haloperidol-Induced Catalepsy by Beta-Adrenoceptor Antagonists in Mice
}

\author{
Chiaki HARA and Nobuya OGAWA \\ Department of Pharmacology. Ehime University School of Medicine. \\ Shigenobu-cho, Onsen-gun, Ehime 791-02, Japan \\ Accepted June 5, 1986
}

\begin{abstract}
Several clinical papers have reported that beta-adrenoceptor antagonists were useful in the management of schizophrenia and tardive dyskinesia. The present study examined effects of beta-antagonists on haloperidol (HAL)-induced catalepsy using mice in order to study the relationship between beta-antagonists and central dopaminergic functions. Catalepsy was tested by the standard bar test $30 \mathrm{~min}$ after intraperitoneal treatment of HAL. Beta-antagonists were administered subcutaneously just after HAL-treatment. Propranolol, alprenolol, oxprenolol and pindolol increased the incidence of catalepsy compared to HAL alone. Atenolol, not penetrating into the brain, and the sedative and hypnotic drug chlordiazepoxide did not potentiate it. These results suggest that the potentiation of HAL-catalepsy by beta-antagonists is based on their central action. Therefore, a central betareceptor appears to be implicated in the regulation of the central dopaminergic functions.
\end{abstract}

Applications of beta-adrenoceptor antagonists have been suggested in therapeutic areas such as psychiatry and neurology (1). However, the mechanism of action of betaantagonists on the central nervous system is still unclear.

Recently, striatal beta-receptor has been reported to play a role regulating dopamine (DA) release from DA nerve terminals (2). Several clinical papers have reported that beta-antagonists are useful in the management of schizophrenia and tardive dyskinesia which are implicated to involve DA functions in the brain (3-8). In fact, a central action of neuroleptics has been suggested to be related to beta-receptors in the brain (9). In addition, propranolol when injected into the hypothalamus is capable of eliciting catalepsy similar to chlorpromazine $(10,11)$. These reports indicate that the central action of beta-antagonists may be involved in DA functions in the brain.

Therefore, the present study examined influences of beta-antagonists on haloperidolinduced catalepsy in mice in order to study the interaction between the central action of beta-antagonists and central DA functions.

\section{Materials and Methods}

Animals: Male ICR mice ( 8 weeks old) supplied from Japan Clea Laboratory Co., Ltd. were used as subjects. They were housed in a temparature-controlled room $\left(23 \pm 1{ }^{\circ} \mathrm{C}\right)$ with a 12:12 light-dark cycle (light on at 08:00 AM). They were allowed free access to food and water.

Procedure: The experiments were conducted during 13:00-17:00 in order to eliminate the possible effect of circadian rhythm on DA functions in the brain (12). In addition, procedures on control and experimental groups were performed in parallel to minimize sources of variation. Catalepsy was measured by a standard bar test, and it was defined by mice keeping the imposed posture placing both frontal limbs over the horizontal steel bar for over $30 \mathrm{sec}$ (10.11). All mice were used only once in the catalepsy test. In the test, three trials were made in quick succession for each mouse. A $60 \mathrm{sec}$ cut-off was used in the test. The catalepsy test was done $30 \mathrm{~min}$ after HAL- 
treatment in reference to the results of the preliminary experiment. HAL was administered intraperitoneally. Beta-antagonists were treated just after $H A L$-treatment. Drug solutions except HAL were coded so that the experimenter did not know the content.

Drugs: All drugs and their abbreviations used in the present study were as follows: dl-propranolol (PROP, ICI Pharma), atenolol (ATE, ICl Pharma), oxprenolol (OXP, Ciba Geigy Japan), alprenolol (ALP. Fujisawa Pharmaceutical Co.), pindolol (PIN, Sandoz, Switzerland) and chlordiazepoxide (CDP. Yoshitomi Pharmaceutical Industries). These drugs were generously donated. Concerning haloperidol (HAL), the injectable solution for humans (Dainippon Pharmaceutical Co.) was used. To minimize the difference between beta-antagonists in first-pass hepatic metabolism (13), beta-antagonists and related drugs were administered subcutaneously. Drugs except PIN were diluted with saline. PIN was dissolved in diluent and diluted with saline. The injection volume used in the present study was $0.1 \mathrm{ml} / 10 \mathrm{~g}$.

Statistical analysis: Dose-response relationships were estimated by the LitchfieldWilcoxon method (14). Incidence of catalepsy induced by HAL in combination with beta-antagonists was evaluated by a factorial analysis of the 3-way contingency table and the chi-square test (15).

\section{Results}

Figure 1 shows the dose-response relationship of the cataleptogenic effect of HAL and its change in combination with betaantagonists. The cataleptogenic effect of HAL in the present study displayed a linear dose-response regression. PROP. ALP, OXP and PIN dose-dependently shifted the linear dose-response regression to the left as compared to saline.

Table 1 illustrates the ED50 of the cataleptogenic effect of HAL when combined

Fig. 1. Effect of propranolol $(n=8)$, alprenolol $(n=7)$, oxprenolol $(n=7)$ and pindolot $(n=8)$ on haloperidol (HAL)-induced catalepsy in mice. Propranolol was treated s.c. just after the i.p. administration of HAL. Catalepsy was tested by the standard bar test 30 min after HAL treatment.
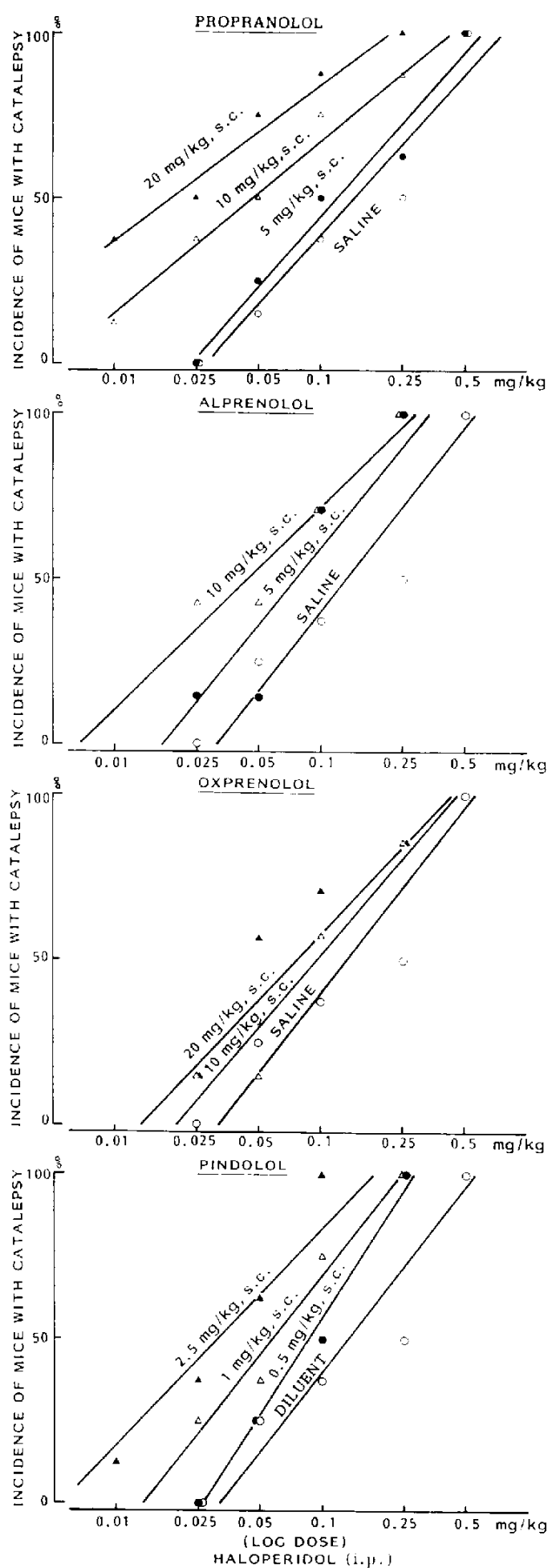
with beta-antagonists. PROP. ALP, OXP and PIN dose-dependently reduced the ED50 value of HAL. The rank order of the potency was as follows: PIN>ALP $\cong P R O P>O X P$.

Table 2 shows the incidence of HALcatalepsy in combination with beta- antagonists. In the PROP study, the factorial analysis showed that HAL as well as PROP treatments were statistically significant [HAL: $F(6.214)=5.79, P<0.01$; PROP: $F(3,214)$ $=2.65, P<0.05]$. In the ALP study, HAL treatment was statistically significant

Table 1. ED50 of the cataleptogenic effect of haloperidol in combination with beta-antagonists

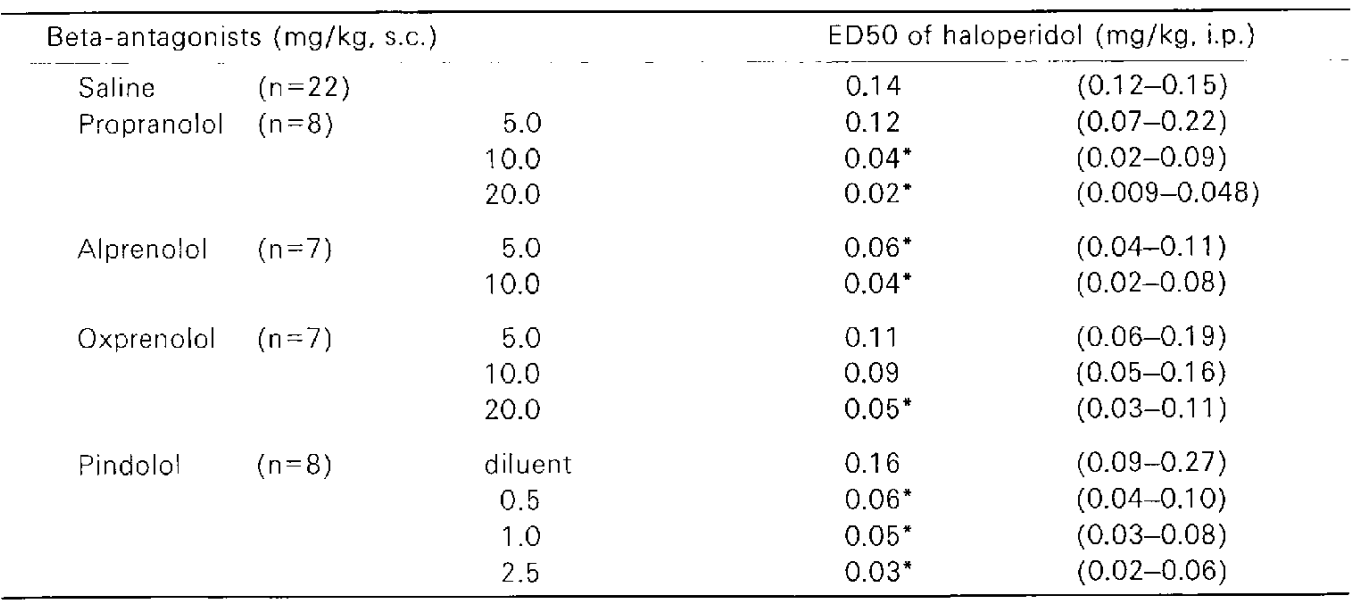

*P<0.05; statistically significant difference from saline or diluent (Litchfield-Wilcoxon method).

Table 2. Incidence of haloperidol-induced catalepsy in combination with beta-antagonists

\begin{tabular}{|c|c|c|c|c|c|c|c|c|}
\hline \multirow{2}{*}{\multicolumn{2}{|c|}{$\begin{array}{l}\text { Beta-antagonists } \\
(\mathrm{mg} / \mathrm{kg} \text {. s.c. })\end{array}$}} & \multicolumn{7}{|c|}{ Haloperidol (mg/kg, i.p.) } \\
\hline & & saline & \multirow{2}{*}{$\begin{array}{l}0.01 \\
0 / 8 \\
0 / 8\end{array}$} & \multirow{2}{*}{$\begin{array}{c}0.025 \\
0 / 8\end{array}$} & \multirow{2}{*}{$\frac{0.05}{2 / 8}$} & \multirow{2}{*}{$\frac{0.1}{3 / 8}$} & \multirow{2}{*}{$\begin{array}{l}0.25 \\
4 / 8\end{array}$} & \multirow{2}{*}{$\frac{0.5}{8 / 8}$} \\
\hline Propranolol & saline & $0 / 8$ & & & & & & \\
\hline & 5.0 & $0 / 8$ & $0 / 8$ & $0 / 8$ & $2 / 8$ & $4 / 8$ & $5 / 8$ & $8 / 8$ \\
\hline & 10.0 & $1 / 8$ & $1 / 8$ & $3 / 8$ & $4 / 8$ & $6 / 8$ & $7 / 8$ & $8 / 8$ \\
\hline & 20.0 & $2 / 8$ & $3 / 8$ & $4 / 8$ & $6 / 8$ & $7 / 8$ & $8 / 8$ & $8 / 8$ \\
\hline & 40.0 & $3 / 8$ & & & & & & \\
\hline & 80.0 & $-\dagger$ & & & & & & \\
\hline \multirow[t]{4}{*}{ Alprenolol } & saline & $0 / 7$ & & $0 / 7$ & $0 / 7$ & $3 / 7$ & $6 / 7$ & \\
\hline & 5.0 & $0 / 7$ & & $1 / 7$ & $1 / 7$ & $6 / 7$ & $7 / 7$ & \\
\hline & 10.0 & $2 / 7$ & & $3 / 7$ & $3 / 7$ & $5 / 7$ & $7 / 7$ & \\
\hline & 20.0 & $2 / 7$ & & $4 / 7$ & $7 / 7$ & $6 / 7$ & $7 / 7$ & \\
\hline \multirow[t]{4}{*}{ Oxprenolol } & saline & $0 / 7$ & & $0 / 7$ & $0 / 7$ & $2 / 7$ & $6 / 7$ & $7 / 7$ \\
\hline & 5.0 & $0 / 7$ & & $1 / 7$ & $1 / 7$ & $2 / 7$ & $5 / 7$ & $7 / 7$ \\
\hline & 10.0 & $0 / 7$ & & $1 / 7$ & $1 / 7$ & $2 / 7$ & $5 / 7$ & $7 / 7$ \\
\hline & 20.0 & $1 / 7$ & & $1 / 7$ & $4 / 7$ & $5 / 7$ & $6 / 7$ & $7 / 7$ \\
\hline \multirow[t]{4}{*}{ Pindolol } & diluent & $0 / 8$ & & $0 / 8$ & $1 / 8$ & $3 / 8$ & $5 / 8$ & \\
\hline & 0.5 & $0 / 8$ & & $0 / 8$ & $2 / 8$ & $4 / 8$ & $8 / 8$ & \\
\hline & 1.0 & $0 / 8$ & & $2 / 8$ & $3 / 8$ & $6 / 8$ & $8 / 8$ & \\
\hline & 2.5 & $1 / 8$ & & $3 / 8$ & $5 / 8$ & $8 / 8$ & $8 / 8$ & \\
\hline
\end{tabular}

tCatalepsy could not be estimated because of induction of muscle relaxation. 


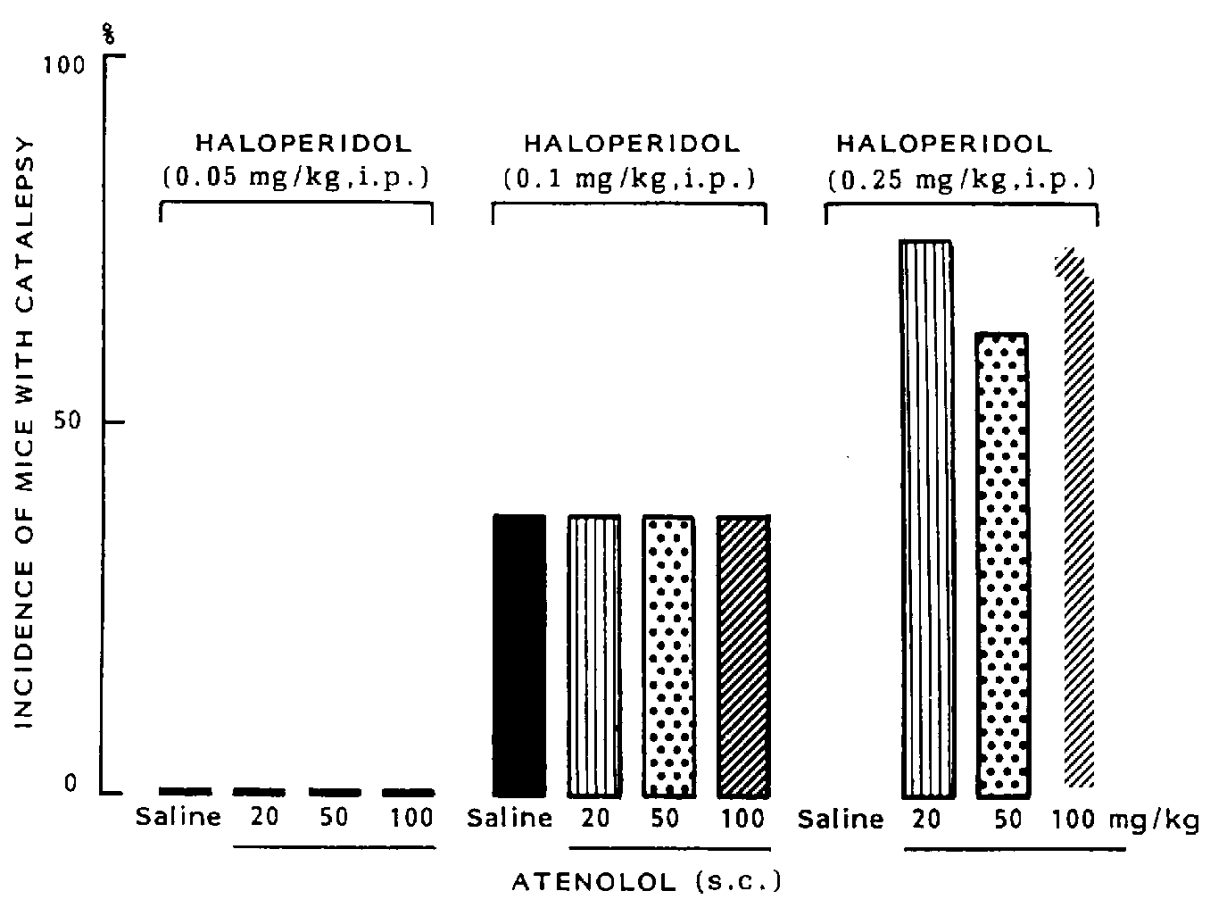

Fig. 2. No influence of atenolol on haloperidol (HAL)-catalepsy in mice. Atenolol was administered s.c. just after HAL treatment. Each group consists of 8 mice.

$[F(4,132)=9.12, P<0.01] . \quad$ ALP treatment also was statistically significant $[F(3,132)$ $=4.36, P<0.01]$. In the OXP study, HAL treatment was significant $[F(5,159)=37.94$, $P<0.01]$. OXP treatment was significant $[F(3,159)=3.36, P<0.05]$. In the PIN study. $H A L$ treatment was significant $[F(4,152)$ $=33.45, P<0.01]$, and PIN treatment was significant $[F(3,152)=9.45, P<0.01]$. These results indicate that combination of betaantagonists with HAL increases the incidence of catalepsy compared to HAL alone as well as beta-antagonists alone. On the other hand, the treatment of beta-antagonists alone did not significantly show the cataleptogenic effect (chi-square test). In the case of a high dose of PROP (80 $\mathrm{mg}$ ), the catalepsy test could not be done because of muscle relaxation.

Figure 2 shows effect of ATE on the cataleptogenic effect of HAL. According to the factorial analysis, $\mathrm{HAL}$ treatment was significant $\quad[F(4.152)=33.39 . \quad P<0.01]$. whereas ATE treatment was not significant.

Figure 3 illustrates effects of CDP on the cataleptogenic effect of HAL. HAL treatment, but not CDP, was statistically significant $[F(4.112)=34.0, P<0.01]$. In the case of $10 \mathrm{mg}$ of CDP. the catalepsy test could not be done because it induced muscle relaxation (data are not shown).

\section{Discussion}

The present study examined effects of beta-adrenoceptor antagonists on HALcatalepsy in mice in order to clarify the mechanism of the central action of betaantagonists. The results of the present study clearly showed that beta-antagonists potentiated HAL-catalepsy. That is, PROP. ALP, OXP and PIN readily penetrating the bloodbrain barrier (16-18) revealed the potentiating effect, whereas ATE not penetrating into the brain $(16,19)$ did not show such an effect. Therefore, these findings suggest that the potentiation of HAL-catalepsy by betaantagonists is based on their central action.

Beta-antagonists possess several pharmacological actions such as beta-receptor blockade, membrane stabilizing effect. 


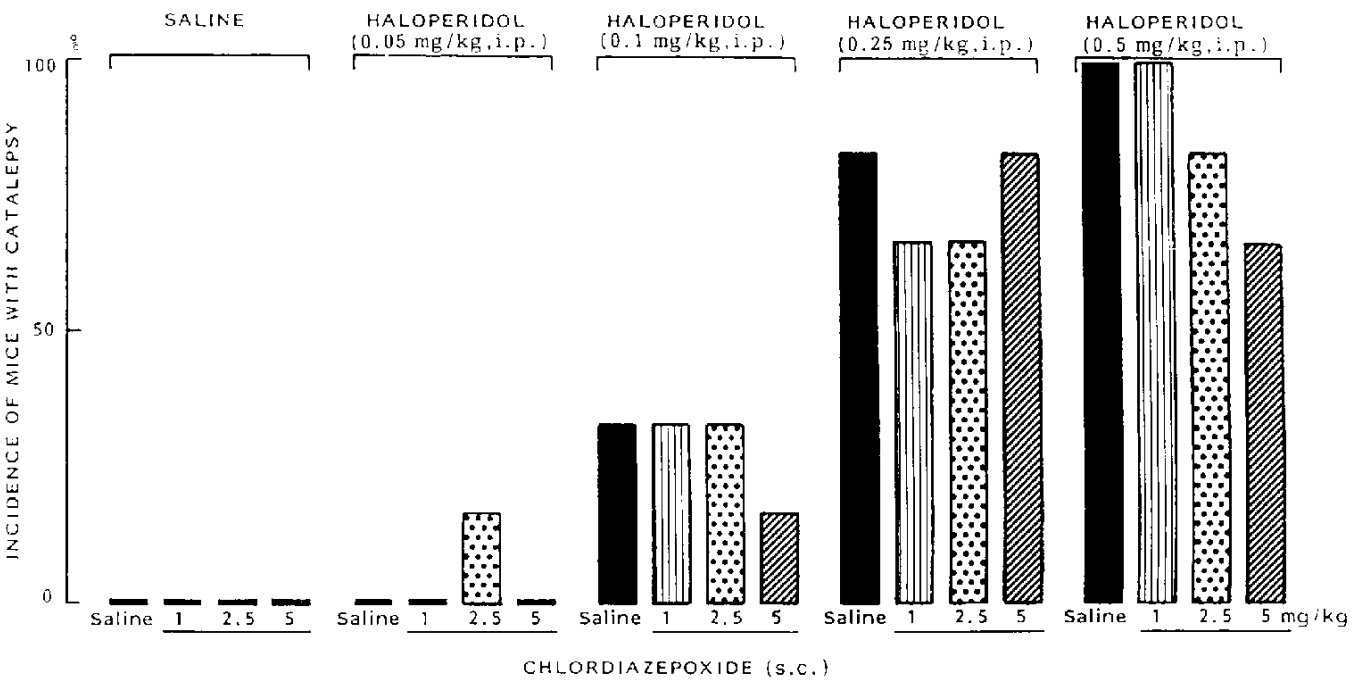

Fig. 3. No influence of chlordiazepoxide on haloperidol (HAL)-catalepsy in mice. Chlordiazepoxide was administered S.c. just after HAL treatment. Each group consists of 6 mice.

intrinsic sympathomimetic activity, and depressive effect on the central nervous system (CNS). PROP has a CNS depressive effect such as an anticonvulsive effect, suppression of fighting behavior and enhancement of sleeping time induced by hexobarbiton ( 20 . 21). These effects have been suggested to be unrelated to the beta-receptor blockade $(20,21)$. These depressive effects also resemble the central action of benzodiazepines like CDP. Therefore, in order to examine the interaction between the potentiation of HAL-catalepsy and the CNS depressant action, the influence of CDP on HAL-catalepsy was studied in the present study. The result showed that CDP did not enhance the cataleptogenic effect of HAL; and rather, the combination of CDP with $\mathrm{HAL}$ seemed to exaggerate their CNS depressant action because 2.5 and $5.0 \mathrm{mg}$ of CDP decreased the incidence of HALcatalepsy in combination with $0.5 \mathrm{mg}$ of $\mathrm{HAL}$ (Fig. 3). Moreover, the catalepsy test of mice treated with $10 \mathrm{mg}$ of CDP could not be done because of muscle relaxation (data are not shown). Therefore, the potentiation of HAL-catalepsy by beta-antagonists found in the present study does not seem to be based on their CNS depressive effect. The clinical study indicated that plasma levels of chlor- promazine and its metabolites were markedly increased in combination with propranolol (19). The mechanism is considered to be due to competition for hydroxylating enzymes between propranoiol and chlorpromazine. However, there is no paper describing such an interaction between HAL and betaantagonists. In the present study, the rank order of the potentiation of HAL-catalepsy by beta-antagonists was $P \mid N>A L P \geqq$ $P R O P>O X P$ (Table 1), while that of their beta-blockade was $P I N>P R O P \geq O X P \geq A L P$ $(13,18,22)$. On the other hand, the degree of CNS penetration of beta-antagonists is known to correspond to their lipid solubility (16): Its rank order is as follows: PROP $>$ ALP $>$ OXP>PIN (23). Therefore, the potency of the potentiation by betaantagonists in the present study appears to be based on the following two factors: betablockade and CNS penetration. In addition, since PIN. which is eliminated from the body by renal excretion as well as hepatic metabolism in contrast to PROP. ALP and OXP. was the most potent in the potentiation of HAL-catalepsy, the pharmacokinetic interaction does not seem to play an important role in the potentiation. The membrane stabilizing effect also does not seem to be implicated in the potentiation by beta- 
antagonists, since PIN, whose membrane stabilizing effect is the weakest compared to the other beta-antagonists used in the present study (22), was the most effective in the potentiation of HAL-catalepsy; and in addition, we noticed that ATE which does not have a membrane stabilizing effect potentiated HAL-catalepsy when injected intraventricularly in rats (manuscript in preparation). Therefore, the potentiation by beta-antagonists in the present study appears to be based on their central action due to their beta-receptor blocking action, although the pharmacokinetic interaction between $\mathrm{HAL}$ and beta-antagonists can not yet be excluded from the factors which may participate in the potentiation of HAL-catalepsy by betaantagonists.

In conclusion, the findings in the present study suggest that beta-antagonists may possess a suppressive effect on DA functions in the brain similar to neuroleptics. This also appears to support the results of Reisine et al. (2).

Acknowledgements: We thank Dr. Shigeyuki Nakano for helpful suggestions with regards to the pharmacokinetic aspects. We also thank Dr. Shigehiro Ohdo for coding the drug solutions and thank Miss Misuzu Kurokawa for taking care of the animals and for typing the manuscrip:

\section{References}

1 Hayes, P.E. and Schulz, S.C.: The use of betaadrenergic blocking agents in anxiety disorders and schizophrenia. Pharmacotherapy 3, 101-117 (1983)

2 Reisine, T.D., Chesselet, M.F., Leubetzki, C., Chēramy, A. and Glowinski, J.: A role for striatal beta-adrenergic receptors in the regulation of dopamine release. Brain Res. 241, 123-130 (1982)

3 Atsmon, A., Blum, I., Wijsenbeck, H., Maoz, B., Steiner, M. and Ziegelman, G.: The short term effects of adrenergic blocking agents in a small group of psychotic patients. Psychiatrica Neurologia Neurochirurgia 74, 251-258 (1971)

4 Yorkston, N.Z., Zaki, S.A., Malik, M.K.U., Morrison, R.C. and Harvard, C.W.H.: Propranolol and the control of schizophrenic symptoms. Br. Med. J. 4, 633-635 (1974)

5 Van Zerssen, D.: Beta-adrenergic blocking agents in the treatment of psychoses. Adv. Clin. Pharmacol. 12, 105-114 (1976)
6 Yorsston, N.Z., Themen, J.F.A. and Harvard, C.W.H.: Propranolol to control schizophrenic symptoms: 55 patients. Adv. Clin. Pharmacol. 12, 91-104 (1976)

7 Shepherd, G.P.: High-dose propranolol in schizophrenia. Br. J. Psychiatry 134, 470-476 (1979)

8 Pugh, C.R., Steinert, J. and Priest, R.G.: Propranolol in schizophrenia: A double blind. placebo controlled trial of propranolol as an adjunct to neuroleptic medication. Br. J. Psychiatry 143, 151-155 (1983)

9 Weiss, B. and Greenberg. L.H.: Modulation of beta-adrenergic receptors and calmodulin following acute and chronic treatment with neuroleptics. Adv. Biochem. Psychopharmacol. 24, $139-149$ (1980)

10 Hara, C., Watanabe, S. and Ueki, S.: Effects of psychotropic drugs microinjected into the hypothalamus on muricide. catalepsy and cortical $E E G$ in $O B$ rats. Pharmacol. Biochem. Behav. 18, 423-431 (1983)

11 Hara, C., Watanabe, S. and Ueki, S.: Antimuricide mechanisms of chlorpromazine and imipramine in $\mathrm{OB}$ rats: Adrenoceptors and hypothalamic functions. Pharmacol. Biochem. Behav. 21, 267-272 (1984)

12 Nakano, S., Hara, C. and Ogawa, N.: Circadian rhythm of apomorphine-induced stereotypy in rats. Pharmacol. Biochem. Behav. 12, 459-461 (1980)

13 Simpson, F.O.: Hypertensive disease. In Drug Treatment, Edited by Avery, G.S., p. 638-782, ADIS Press, Sydney and New York (1980)

14 Litchfield, J.T. and Wilcoxon, F.: A simplified method of evaluating dose-effect experiments. J. Pharmacol. Exp. Ther. 96, 99-113 (1949)

15 Siegel, S.: Nonparametric Statistics for the Behavioral Sciences. McGraw-Hil! Kogakusha, Tokyo (1956)

16 Street, J.A., Hemsworth, B.A., Roach, A.G. and Day, M.D.: Tissue levels of several radiolabelled beta-adrenoceptor antagonists after intravenous administration in rats. Arch. Int. Pharmacodyn. Ther. 237, 180-190 (1979)

17 Neil-Dwyer, G., Bartlett, J., McAinsh, J. and Gruickshank, J.M.: Beta-adrenoceptor blockers and the blood-brain barrier. Br. J. Clin. Pharmacol. 11, 549-553 (1981)

18 Kendall, M.J. and Smith, S.R.: Adrenergic blocking agents. J. Clin. Hosp. Pharm. 8, 155173 (1983)

19 Peet, M., Middlemiss, D.N. and Yates, R.A.: Propranolol in schizophrenia. II. Clinical and biochemical aspects of combinating propranolol 
with chlorpromazine. Br. J. Psychiatry 138, 112 117 (1981)

20 Murmann, W., Almirante, L. and Saccani-Guelfi, $M .:$ Central nervous system effects of four betaadrenergic receptor blocking agents. J. Pharm. Pharmacol. 18, 317-318 (1966)

21 Murmann, W., Almirante, L. and SaccaniGuelfi, M.: Effects of hexobarbitone, ether, morphine, and urethane upon the acute toxicity of propranolol and $D(-)$-INPEA. J. Pharm. Pharmacol. 18, 692-694 (1966)
22 Weiner, N.: Drugs that inhibit adrenergic nerves and block adrenergic receptors. In The Pharmacological Basis of Therapeutics, Edited by Goodman Gilman. A., Goodman, L.S. and Gilman. A.. p. 176-210. MacMillan Publishing Co. Inc. New York (1980)

23 Johnsson, G. and Regardh, C.G.: Clinical Pharmacokinetics of beta-adrenoceptor blocking drugs. Clin. Pharmacokinetics 1, 233-263 (1976) 